\title{
Nanodiamond-Based Tests Systems for Biochemical Determination of Glucose and Cholesterol
}

\author{
Nikita O. Ronzhin ${ }^{1,2}$, Alexey V. Baron ${ }^{1,2}$, Ekaterina S. Mamaeva ${ }^{1,2}$, Alexey P. Puzyr ${ }^{1,2}$, \\ Vladimir S. Bondar, ${ }^{1,2}$ \\ ${ }^{1}$ Institute of Biophysics SB RAS, Krasnoyarsk, Russia; ${ }^{2}$ Siberian Federal University, Krasnoyarsk, Russia. \\ Email:roniol@mail.ru
}

Received March $30^{\text {th }}, 2013$; revised May 21 ${ }^{\text {st }}, 2013$; accepted June $5^{\text {th }}, 2013$

Copyright (C) 2013 Nikita O. Ronzhin et al. This is an open access article distributed under the Creative Commons Attribution License, which permits unrestricted use, distribution, and reproduction in any medium, provided the original work is properly cited.

\begin{abstract}
Model test-systems for biochemical determination of glucose and cholesterol are designed by covalent coupling of enzymes to the surface of modified nanodiamonds (MND). In both cases after immobilization on MND the enzymes exhibit activity and catalyze the formation of a colored product in the chain of successive enzymatic reactions of oxidative azocoupling $\left(\mathrm{H}_{2} \mathrm{O}_{2}\right.$ - 4-aminoantipyrine-phenol). Produced MND-enzymes complexes: function in DI water and various buffers, over a wide range of temperature and $\mathrm{pH}$, provide for the linear product yield over a broad concentration range of analyzed substances, make possible to test cholesterol and glucose in vitro many times, exhibit functional activity after long storage at $+4^{\circ} \mathrm{C}$.
\end{abstract}

Keywords: Nanodiamond; Test-System; Glucose; Cholesterol

\section{Introduction}

Detonation nanodiamonds generate much interest in researchers, because physical-chemical properties of these nanoparticles (small size, reactive surface, low toxicity, high biocompatibility, etc.) make possible to forecast a broad range of their biomedical applications [1-4]. Among these applications is new biochemical indicator means (including reusable systems) to broaden the inventory of medical diagnostic aids. For experts in the field of interest can be modified nanodiamonds (MND) which form free-dispersed systems and adapted for medical-biological study $[5,6]$. Earlier we showed feasibility of using MND as polyfunctional adsorbents to separate and purify biomolecules [7] and as a basis to design systems for targeted delivery of bioactive substances [8]. Chemically polymorphous active surface of MND featuring high colloidal stability in aqueous media $[9,10]$ suggests its use to develop tools for biochemical diagnosis of components of biological liquids.

In this work, we investigated the possibility of conjugating MNDs with enzymes to the design of the biochemical diagnostic test-systems for evaluation of cholesterol and glucose.

\section{Materials and Methods}

MND (Brand RUDDM 0 - 125, $\mathrm{d}_{50}=49.6 \mathrm{~nm}$ ), produced by "Real Dzerzhinsk" Ltd. (Russia) by known technology $[5,11]$ was used in the work. In experiments we used MND hydrosols with nanoparticle concentration of 10.0 $\mathrm{g} \cdot \mathrm{l}^{-1}$, prepared by addition of DI water to a MND powder sample. Milli-Q system (Millipore, USA) was used for producing DI water.

Chemical reagents used in the study: 4-aminoantipyrine (1-phenyl-2,3-dimethyl-4-aminopyrazolone) (4-AAP) and high-quality D-glucose (Reakhim, Russia), phenol (Fluka, Germany), cholesterol calibrator (Vital Diagnostic, S.-Petersburg, Russia). Reagents solutions were prepared in situ in DI water.

To develop diagnostic test-systems we used enzymes solutions from Cholesterol-Vital (Vital Diagnostic, S.Petersburg, Russia) and Glucose LS (ProDia International, Germany) kits, served to evaluate the total cholesterol and glucose in blood serum and plasma. For experiments the enzymes solutions were dialyzed against 10 $\mathrm{mM}$ phosphate buffer ( $\mathrm{pH}$ 7.0) by ultrafiltration (Amicon, USA) through a $30 \mathrm{kDa}$ membrane.

Model systems of biochemical diagnosis were made by covalent immobilization of enzymes on the surface of MND particles pre-activated by $\mathrm{p}$-benzoquinone according to the well-known procedure [12-14]. To design glucose determination system two enzymes (glucose oxidase and peroxidase) were simultaneously covalently coupled 
to MND, to design the cholesterol determination systemthree enzymes (cholesterol esterase, cholesterol oxidase and peroxidase). Proteins were immobilized in the presence of $100 \mathrm{mM}$ Na-bicarbonate buffer ( $\mathrm{pH} 8.0$ ). Solutions of respective enzymes were mixed with hydrosols of benzoquinone-activated MND, and the suspensions produced were incubated at room temperature for $1-1.5$ $\mathrm{h}$ being permanently stirred at the rate of $150 \mathrm{rpm}$ (Shaker OS-10, BIOSAN, Latvia). Then the nanoparticles with immobilized enzymes were collected by centrifugation at 16,000 g (Centrifuge 5415R, Eppendorf, Germany) for $10 \mathrm{~min}$ at $10^{\circ} \mathrm{C}$. The sediments were three times washed with $0.25 \mathrm{M} \mathrm{NaCl}$ solution to remove the protein non- specifically adsorbed on MND. For this the nanoparticles were re-suspended each time in a new portion of washing solution and collected by centrifugation under the above conditions. The washed MND with immobilized enzymes were re-suspended in DI to be used in experiments.

Activity of produced diagnostic systems (MND-enzymes complexes) were evaluated with an azocoupling reaction $\left(\mathrm{H}_{2} \mathrm{O}_{2}-4-\mathrm{AAP}\right.$ - phenol) [15]. This reaction is commonly used in medical diagnostics for enzymatic evaluation of physiologically important substances [16] and is attended by formation of stained reaction product (quinoneimine). Glucose determination was provided by two successive biochemical reactions:

$$
\begin{aligned}
& \text { Glucose }+\mathrm{O}_{2}+\mathrm{H}_{2} \mathrm{O} \rightarrow \text { Glucose oxydase } \rightarrow \text { Gluconic acid }+\mathrm{H}_{2} \mathrm{O}_{2} \\
& 2 \mathrm{H}_{2} \mathrm{O}_{2}+\text { Phenol }+4 \text { - AAP } \rightarrow \text { Peroxidase } \rightarrow \text { Quinoneimine }+4 \mathrm{H}_{2} \mathrm{O}
\end{aligned}
$$

Determination of cholesterol comprises three successive biochemical reactions:

$$
\begin{gathered}
\text { Cholesterol ester } \rightarrow \text { Cholesterol esterase } \rightarrow \text { Cholesterol } \\
\text { Cholesterol }+\mathrm{O}_{2} \rightarrow \text { Cholesterol oxidase } \rightarrow \text { Cholestenone }+\mathrm{H}_{2} \mathrm{O}_{2} \\
2 \mathrm{H}_{2} \mathrm{O}_{2}+\text { Phenol }+4 \text { - AAP } \rightarrow \text { Peroxidase } \rightarrow \text { Quinoneimine }+4 \mathrm{H}_{2} \mathrm{O}
\end{gathered}
$$

when activity of the test-systems was measured, the final concentration of ingredients in $1 \mathrm{ml}$ volume of reaction mixture was: $0.56 \mathrm{mg} \cdot \mathrm{ml}^{-1}$ of phenol, $0.10 \mathrm{mg} \cdot \mathrm{ml}^{-1}$ of 4-AAP and $50 \mu \mathrm{l}$ of MND-enzymes suspension (final concentration of nanoparticles $\left.0.5 \mathrm{~g} \cdot 1^{-1}\right)$. After the reaction was started by adding an analyte (cholesterol or glucose-final concentration in reaction mixture $1 \mathrm{mg} \cdot \mathrm{ml}^{-1}$ ), the samples were intensively agitated for 3 - 5 seconds on Vortex-Genie 2 g-560E (Scientific Industries, Inc., USA) and incubated at room temperature. Concentration of cholesterol and glucose in the reaction mixture, its temperature, $\mathrm{pH}$ and incubation time were varied to study dependencies of product formation.

Following the reaction, the samples were centrifuged under the above conditions to remove MND-enzymes complexes from the reaction mixture. The produced supernatants were collected for spectral analysis of the stained product by measuring the optical density at a wavelength $506 \mathrm{~nm}$ (UV/VIS spectrophotometer UVIKON 943, Kontron Instruments, Italy).

A multiple use the indicator systems was checked as follows. Following the reaction, the samples were centrifuged and supernatants were collected for spectral analysis of the stained product. The precipitates were washed twice with $20 \mathrm{mM}$ phosphate buffer ( $\mathrm{pH}$ 7.0) to remove the reaction product. The washed MND-enzymes complexes were re-suspended in DI water and ingredients required to start the reaction was added again.

\section{Results and Discussion}

General principle of biochemical diagnostic systems bas- ed on MND and enzymes is shown on a hypothetical scheme (Figure 1).

The substance to be defined (analyte) transforms in a chain of successive biochemical reactions catalyzed by enzymes $\mathrm{E} 1 \rightarrow \mathrm{E} 2 \rightarrow \ldots \rightarrow$ En immobilized on nanoparticles into respective products $\mathrm{P} 1 \rightarrow \mathrm{P} 2 \rightarrow \ldots \rightarrow \mathrm{Pn}$. The final product $(\mathrm{Pn})$ is stained and is easily detected by spectral analysis.

Model systems for biochemical diagnosis of glucose and cholesterol were designed by covalent coupling of enzymes on p-benzoquinone activated MND particles. To prevent denaturation of biopolymers (e.g. proteins) in their immobilization on a carrier, its surface is first activated-this makes possible to bind biomolecules under relatively mild conditions [13]. Reaction with chemical activator generates electrophilic groups on the carrier's

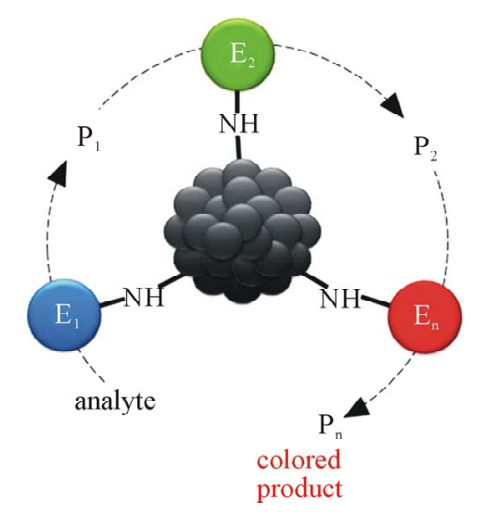

Figure 1. Hypothetical scheme of biochemical diagnostic test-systems designed on the basis of MDN and enzymes. 
surface, which form covalent bonds with nucleophilic groups of molecules of the immobilized biopolymer, e.g. protein amino groups. A particular case of such a reaction is preliminary activation of the carrier containing surface-OH groups by p-benzoquinone and subsequent coupling of a protein $[12,14]$. Earlier MND surface was shown to have hydroxyl groups [10], therefore in this work the enzymes were covalently coupled to the nanoparticles pre-activated with p-benzoquinone. Methods of MND activation by p-benzoquinone was described in detail earlier [8].

Development of model systems for determination of glucose and cholesterol found out that in both cases enzymes covalently immobilized on MND particles exhibit activity. Indicator systems (MND-enzymes complexes) catalyze formation of stained product with addition of the analyte (cholesterol or glucose) into the reaction mixture. It was shown that both systems provide practically a linear yield of product at temperatures of $20^{\circ} \mathrm{C}-22^{\circ} \mathrm{C}$ in the time interval of 5 - 40 minutes (Figure 2).

It is worthy of note that in the absence of analyzed substances the systems were not observed to form the product.

Experiments showed (Figure 3) that both diagnostic systems can function over a wide temperature range. From the data it is apparent that activity of glucose determination system slightly increases in temperature range of $30^{\circ} \mathrm{C}-42^{\circ} \mathrm{C}$ (the product yield is higher by about $10 \%$ ), as compared to its activity at temperature $22^{\circ} \mathrm{C}$. Meanwhile, the temperature optimum for the activity of cholesterol determination system is around $50^{\circ} \mathrm{C}$ (Figure 3). At this temperature the product yield is considerably higher (about $4-4.5$ times) as compared to its formation at $20^{\circ} \mathrm{C}$. However, at temperature $20^{\circ} \mathrm{C}$ the yield of product is quite sufficient for spectral testing.

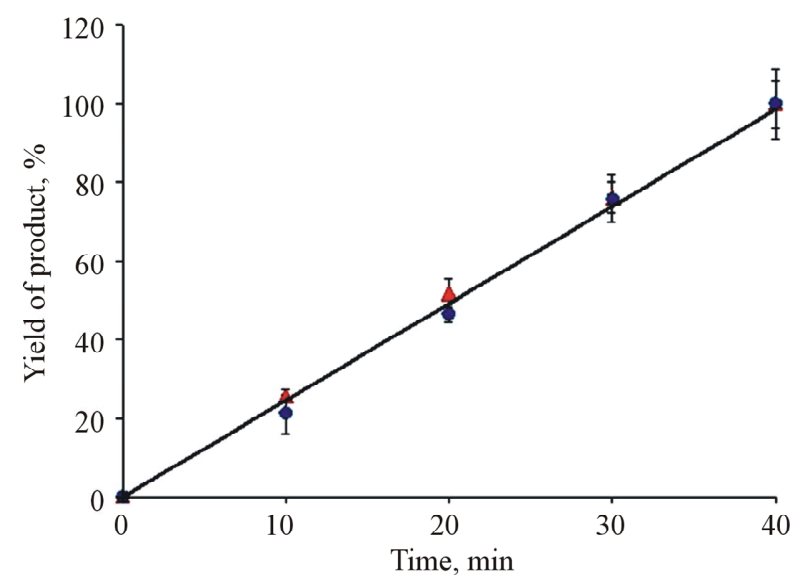

Figure 2. Product formation in the reaction of hydrogen peroxide-4-AAP-phenol catalyzed by cholesterol (triangles) and glucose (circles) determination test-systems vs. time. The data are normalized for maximum product yield in measurements of glucose and cholesterol, respectively.
This might be explained by the temperature optimum for the operation of enzymes comprised in the diagnostic systems.

The MND-enzymes complexes can function over a broad $\mathrm{pH}$ range and exhibit high activity under slightly acidic and neutral conditions of the medium (Figure 4).

It is evident that both diagnostic systems show similar efficiency in DI water as well. The cholesterol and glucose determination systems were also shown to efficiently function in various buffers with neutral $\mathrm{pH}$ value. This was demonstrated on five different buffers with 20 $\mathrm{mM}$ concentration: phosphate, ammonium acetate, bistris propane, sodium acetate and tris (Figure 5).

The glucose indication system was shown to ensure practically similar yield of the product in all mentioned buffers. It should be noted that the sodium acetate and tris buffers were observed to slightly (about $5 \%-10 \%$

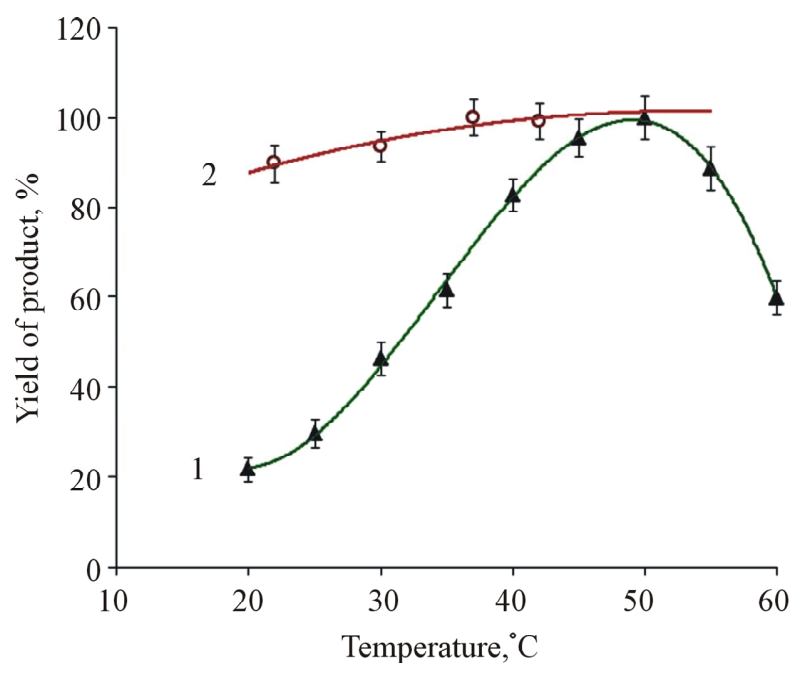

Figure 3. Product yield in reaction catalyzed by cholesterol (1) and glucose (2) determination test-systems vs. temperature. The data are normalized for maximum product yield in measurements of glucose and cholesterol, respectively.

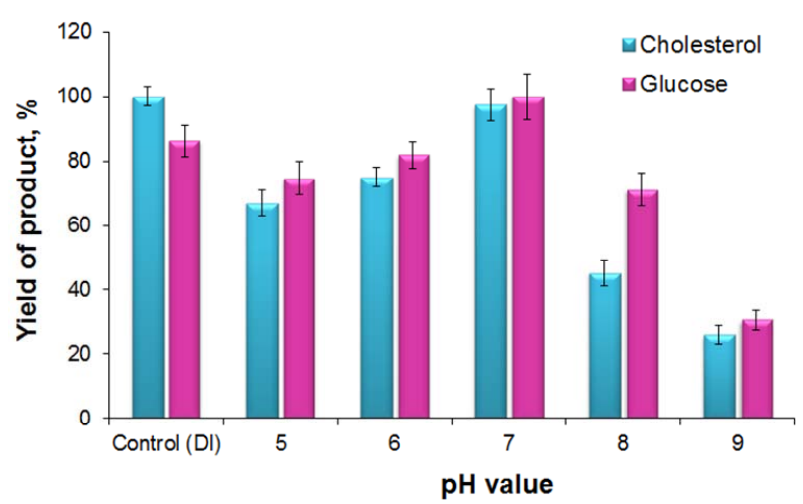

Figure 4. Product yield in reaction catalyzed by cholesterol and glucose determination test-systems vs. pH. Control (DI) formation of product catalyzed by test-systems in DI water. The data are normalized for maximum product yield in measurements of glucose and cholesterol, respectively. 


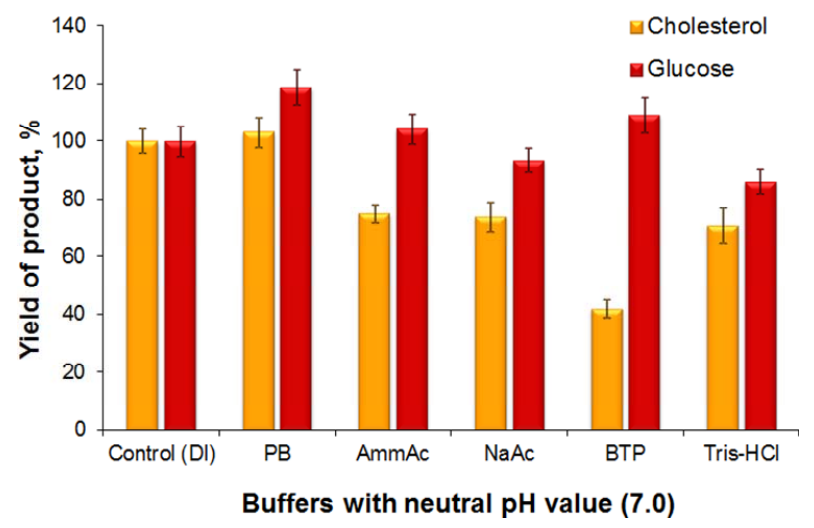

Figure 5. Product yield in reaction catalyzed by cholesterol and glucose determination test-systems in different $20 \mathrm{mM}$ buffers with neutral pH (7.0): PB-phosphate buffer, AmAcammonium acetate buffer, NaAc-sodium acetate buffer, BTPbis-tris-propane buffer, Tris-tris buffer. Control (DI)-yield of product catalyzed by test-systems in DI water. The data are normalized for product yield in DI water in measurements of glucose and cholesterol, respectively.

and $10 \%-15 \%$, respectively) decrease the product yield as compared to its formation in DI water. At the same time the cholesterol indication system turned out to be more sensitive to the buffer composition (Figure 5). It can be seen, that the yield decreases in the ammonium acetate and sodium acetate (about $25 \%-30 \%$ ) and especially in bis-tris propane (up to $50 \%-60 \%$ ) buffers, as compared to its yield in DI water. On the whole the presented results indicate that optimum for the operation of both systems is the phosphate buffer.

The developed biochemical diagnostic systems have been found to provide for linear product yield over a broad concentration range of analyzed substances (Figure 6). For the cholesterol determination system this is observed in the range of low $\left(0.01-0.2 \mathrm{mg} \cdot \mathrm{ml}^{-1}\right)$ concentrations of the analyte. At this, the glucose determination system ensures the linear product yield in glucose concentration range $0.01-1.5 \mathrm{mg} \cdot \mathrm{ml}^{-1}$, which exceeds its physiological values in human blood. These results have significant practical value because they make possible to suggest applicability of the designed test-systems in medical diagnosis of physiologically important substances.

Experiments demonstrated feasibility of reusing the developed test-systems to evaluate cholesterol and glucose in vitro (Figure 7).

However, as seen from the presented data, with successive measurements a gradual decrease of the product yield is observed in both cases. The observed changes may be due to a partial inactivation of enzymes when the test-systems are reused many times. Specifically, this can take place at the stages of multiple re-suspension and sedimentation of MND-enzymes complexes by centrifugation to remove the reaction product. Nevertheless, it

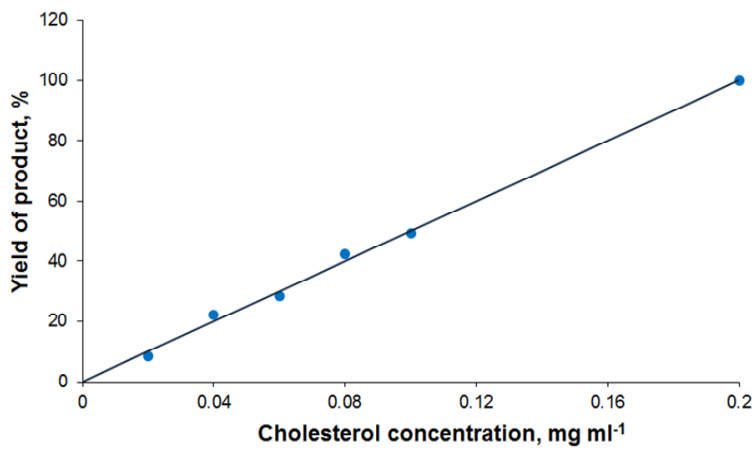

(a)

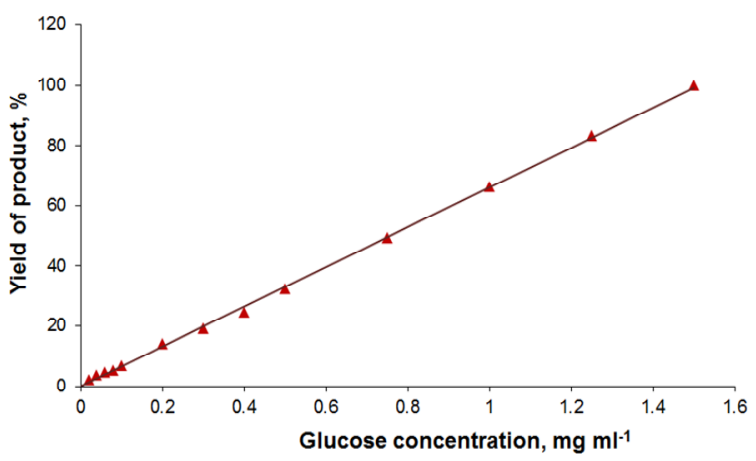

(b)

Figure 6. Product formation in reaction catalyzed by MNDenzymes test-systems depending on the cholesterol (a) and glucose (b) concentration. The data are normalized for maximum product yield in measurements of glucose and cholesterol, respectively.

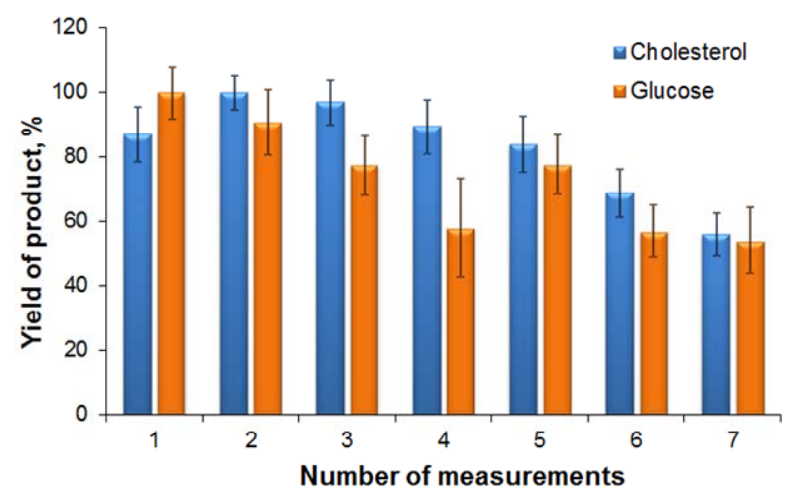

Figure 7. Product yield in multiple re-use of test-systems to determination cholesterol and glucose. The data are normalized for maximum product yield in measurements of glucose and cholesterol, respectively.

should be noted, that the designed MND-enzymes complexes are quite stable. This is supported by the fact that the cholesterol and glucose indication systems are functionally active for, at least, two months when stored in DI water at temperature $+4^{\circ} \mathrm{C}$.

\section{Conclusion}

The work demonstrated feasibility of employing MND to 
develop systems for biochemical diagnosis of physiologically important substances. Covalent coupling of enzymes onto benzoquinone activated MND made it possible to design model systems of cholesterol and glucose determination. The enzymes immobilized on the nanoparticle surface have been found to exhibit activity and catalyze formation of stained product in the chain of successive enzymatic reactions. The produced MND-enzyme complexes have been shown to function over a wide range of temperatures and $\mathrm{pH}$, in DI water and different buffers, provide for the linear yield of the product over a broad concentration range of analyzed substances, make possible to re-test many times, preserve activity for a long time. In our opinion, further optimization of conditions for development of reusable test-systems based on MND and enzymes can bring into being a new class of efficient indicators for medical diagnostic.

\section{Acknowledgements}

The study has been made with financial support of Presidium of the Russian Academy of Sciences (Program No. 24, Project 57 (3.6.3)).

\section{REFERENCES}

[1] K. B. Holt, "Diamond at the Nanoscale: Applications of Diamond Nanoparticles from Cellular Biomarkers to Quantum Computing," Philosophical Transactions of the Royal Society A, Vol. 365, No. 1861, 2007, pp. 2845-2861. doi:10.1098/rsta.2007.0005

[2] A. Schrand, S. A. C. Hens and O. A. Shenderova, "Nanodiamond Particles: Properties and Perspectives for Bioapplications," Critical Reviews in Solid State and Materials Sciences, Vol. 34, No. 1-2, 2009, pp. 18-74. doi:10.1080/10408430902831987

[3] J. M. Say, C. van Vreden, D. J. Reilly, L. J. Brown, J. R. Rabeau and N. J. C. King, "Luminescent Nanodiamonds for Biomedical Applications," Biophysical Reviews, Vol. 3, No. 4, 2011, pp. 171-184. doi:10.1007/s12551-011-0056-5

[4] V. N. Mochalin, O. Shenderova, D. Ho and Y. Gogotsi, "The Properties and Applications of Nanodiamonds," $\mathrm{Na}$ ture Nanotechnology, Vol. 7, No. 1, 2012, pp. 11-23. doi:10.1038/nnano.2011.209

[5] V. S. Bondar and A. P. Puzyr, "Nanodiamonds for Biological Investigations," Physics of the Solid State, Vol. 46, No. 4, 2004, pp. 716-719. doi:10.1134/1.1711457
[6] A. P. Puzyr, A. V. Baron, K. V. Purtov, E. V. Bortnikov, N. N. Skobelev, O. A. Mogilnaya and V. S. Bondar, "Nanodiamonds with Novel Properties: A Biological Study," Diamond and Related Materials, Vol. 16, No. 12, 2007, pp. 2124-2128. doi:10.1016/j.diamond.2007.07.025

[7] V. S. Bondar, I. O. Pozdnyakova and A. P. Puzyr, "Applications of Nanodiamonds for Separation and Purification of Proteins," Physics of the Solid State, Vol. 46, No. 4, 2004, pp. 758-760. doi:10.1134/1.1711468

[8] K. V. Purtov, A. I. Petunin, A. E. Burov, A. P. Puzyr and V. S. Bondar, "Nanodiamonds as Carriers for Address Delivery of Biologically Active Substances," Nanoscale Research Letters, Vol. 5, No. 3, 2010, pp. 631-636. doi:10.1007/s11671-010-9526-0

[9] A. P. Puzyr, V. S. Bondar, A. A. Bukayemsky, G. E. Selyutin and V. F. Kargin, "Physical and Chemical Properties of Modified Nanodiamonds," NATO Science Series II: Mathematics, Physics and Chemistry, Vol. 192, 2005, pp. 261-270. doi:10.1007/1-4020-3322-2_20

[10] N. Gibson, O. Shenderova, T. J. M. Luo, S. Moseenkov, V. Bondar, A. Puzyr, K. Purtov, Z. Fitzgerald and D. W. Brenner, "Colloidal Stability of Modified Nanodiamond Particles," Diamond and Related Materials, Vol. 18, No. 4, 2009, pp. 620-626. doi:10.1016/j.diamond.2008.10.049

[11] A. P. Puzyr and V. S. Bondar, "Method of Production of Nanodiamonds of Explosive Synthesis with an Increased Colloidal Stability,” RU Patent No. 2252192, 2003.

[12] J. Brandt, L. O. Andersson and J. Porath, "Covalent Attachment of Proteins to Polysaccharide Carriers by Means of Benzoquinone," Biochimica et Biophysica Acta-Protein Structure, Vol. 386, No. 1, 1975, pp. 196-202. doi:10.1016/0005-2795(75)90259-7

[13] L. A. Osterman, "Chromatography of Proteins and Nucleic Acids," Nauka, Moscow, 1985.

[14] M.-A. Mateescu, G. Weltrowska, E. Agostinelli, R. SaintAndre, M. Weltrowski and B. Mondovi, "Ready to Use PBenzoquinone-Activated Supports for Biochemical Coupling, with Special Applications for Laccase Immobilization," Biotechnology Techniques, Vol. 3, No. 6, 1989, pp. 415-420. doi:10.1007/BF01875011

[15] A. N. Yeremin, T. V. Semashko and R. V. Mikhailova "Cooxidation of Phenol and 4-Aminoantipyrine, Catalyzed by Polymers and Co-Polymers of Horse Radish Root and Glucose Oxidase of Penicillium Funiculosum 46.1," Applied Microbiology and Biotechnology, Vol. 42, No. 4, 2006, pp. 452-461.

[16] Official Website of the OMB Medical Company. www.omb.ru/products/index.php?f_catalog_id $=123$ 